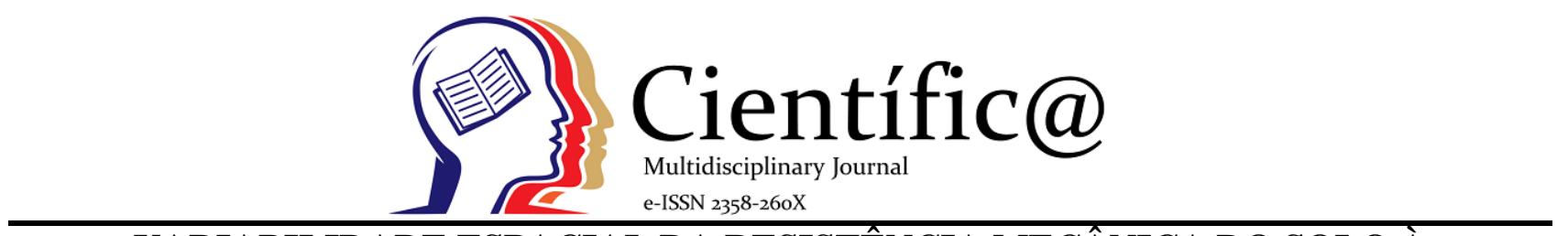

\title{
VARIABILIDADE ESPACIAL DA RESISTÊNCIA MECÂNICA DO SOLO À PENETRAÇÃO NA COLHEITA MECANIZADA DE MILHO PARA SILAGEM
}

\author{
Spatial variability of mechanical resistance of soil to penetration in mechanized harvesting of \\ corn for silage
}

\author{
Ariel Muncio Compagnon ${ }^{1}$; Ivan Henrique Guilherme ${ }^{1}$; Walter José Pereira Filho ${ }^{1}$; Renato \\ Souza Rodovalho ${ }^{1}$; Fernando Henrique Arriel ${ }^{1}$
}

${ }^{1}$ Instituto Federal Goiano Campus Ceres

\section{Info}

Recebido: 05/2019

Publicado: $12 / 2020$

DOI: $10.29247 / 2358-260 X .2020 v 7 i 2.4542$

ISSN: 2358-260X

Palavras-Chave
compactação, geoestatística, mapas de
variabilidade.
Keywords:
compaction, geostatistics, variability maps

\begin{abstract}
Because it is directly related to plant growth, soil mechanical resistance to penetration (RMSP) has been the physical attribute prioritized in studies that study soil compaction. The objective of this study was to verify if the traffic of machines during the harvest of corn for silage entails the need to prepare the soil for the next crop. The AMSY was evaluated in the layers of $0.0-0.10,0.10-0.20$ and $0.20-0.30 \mathrm{~m}$ by means of a penetrograph and the water content of the soil in the layers $0-0.15$ and $0.15-0.30 \mathrm{~m}$, following a sample mesh with 45 points spaced at $20 \mathrm{~m}$, before and after the corn harvest for silage, georeferenced with GPS equipment. The results were submitted to descriptive statistical analysis, analysis of variance and geostatistics. To demonstrate the variability of the
\end{abstract} attributes, thematic maps were made. The analyzes showed low values of RMSP, with mean values of 2.17 $\mathrm{MPa}$. The traffic of machines during the corn harvest caused an increase in the mechanical resistance of the soil to the penetration, but reached levels below that described as critical limit of root penetration, and there is no need for conventional preparation for implantation of the next crop.

\section{Resumo}

Por estar diretamente relacionada ao crescimento das plantas, a resistência mecânica do solo à penetração (RMSP) tem sido o atributo físico priorizado em trabalhos que estudam a compactação do solo. Objetivou-se com esse estudo verificar se o tráfego de máquinas durante a colheita de milho para silagem acarreta na necessidade de preparo do solo para a implantação da próxima cultura. Foi avaliada a RMSP nas camadas de 0,0-0,10,0,10-0,20 e 0,20-0,30 m por meio de um penetrógrafo e o teor de água do solo nas camadas de 0-0,15 e 0,15-0,30 m, seguindo uma malha amostral com 45 pontos espaçados em $20 \mathrm{~m}$, antes e após a colheita do milho para silagem, georreferenciados com equipamento GPS. Os resultados foram submetidos à análise estatística descritiva, análise de variância e geoestatística. Para demonstrar a variabilidade dos atributos foram confeccionados mapas temáticos. As análises mostraram valores baixos de RMSP, com valores médios de 2,17 MPa. 0 tráfego de máquinas durante a colheita do milho causou incremento da resistência mecânica do solo à penetração, porém atingindo níveis abaixo do descrito como limite crítico de penetração das raízes, não havendo necessidade de preparo convencional para implantação da próxima cultura.

\section{INTRODUÇÃO}

Com a modernização da agricultura, o número de máquinas agrícolas que trafegam no campo tem aumentado significativamente ao longo dos anos, o que tem garantido expansão da área cultivada. Entretanto, juntamente com esse crescimento, o problema da compactação do solo vem surgindo sistematicamente em extensas regiões do país, se tornando uma das 
principais causas da degradação da capacidade produtiva de solos agrícolas (Stefanoski et al., 2013).

Segundo Souza et al. (2010), a compactação é um processo caracterizado pela redução do espaço poroso do solo e pelo aumento de sua densidade, sendo o tráfego excessivo de máquinas o principal agente causador desse problema. De acordo com Drescher et al. (2012), a compactação modifica negativamente várias propriedades do solo, como capacidade de penetração das raízes e disponibilidade de água e nutrientes para as plantas, restringindo a taxa de fotossíntese e o crescimento da parte aérea e, consequentemente, o rendimento das culturas.

Uma das atividades onde a compactação do solo é mais evidente é no processo de colheita de milho para produção de silagem, que geralmente é realizado linha por linha havendo tráfego intenso de máquinas e transbordos. Esse evento leva a maioria dos produtores a realizarem o preparo convencional do solo para a implantação de uma nova cultura na área, embora não haja na literatura resultados que mostrem se o tráfego de máquinas durante essa operação acarreta na necessidade de preparo do solo para a próxima safra.

A sondagem do solo para a determinação do estado de compactação é um procedimento imprescindível na análise de sua qualidade física, pois a partir desse indicador mecânico avalia-se a necessidade ou não da subsolagem (Lima et al., 2013). Um dos parâmetros mais utilizados para avaliar a intensidade da compactação do solo é a resistência mecânica do solo à penetração (Oliveira Filho et al., 2015). Esse atributo apresenta forte relação com o crescimento radicular das plantas, sendo influenciado pelo teor de água e pela condição estrutural do solo (Beutler e Centurion, 2003).

Como qualquer outro atributo do solo, a resistência mecânica do solo à penetração pode apresentar elevada variabilidade espacial (Coelho et al., 2012). Nesse contexto, o emprego da geoestatística constitui-se com uma importante ferramenta na análise e descrição da variabilidade espaço temporal, possibilitando a interpretação dos resultados com base na estrutura da variabilidade natural dos atributos, considerando a dependência espacial dentro do intervalo de amostragem (Souza et al., 2010, Batista et al., 2019).

Diante desse contexto, objetivou-se com esse trabalho verificar se o tráfego de máquinas durante a colheita de milho para silagem acarreta na necessidade de preparo do solo para a implantação de uma próxima a cultura.

\section{MATERIAL E MÉTODOS}

O estudo foi realizado no Instituto Federal Goiano - Campus Ceres em área que se encontrava sob pastagem, em torno das coordenadas geográficas latitude $15^{\circ} 20^{\prime} 46^{\prime \prime} \mathrm{S}$ e longitude 49³5’50” O, com altitude média de 561 metros. O solo da área é classificado como Latossolo vermelho de textura muito argilosa (61,1\% de argila). De acordo com a classificação de Köppen, o clima da região é caracterizado como tropical, com inverno seco e verão chuvoso (Aw).

Foi realizado o preparo convencional do solo, constituído de uma subsolagem a $40 \mathrm{~cm}$ de profundidade, gradagem pesada e leve. Logo após, foi feito a semeadura do milho, utilizando semeadoraadubadora da marca Jumil modelo JM2980 PD EX8, regulada para distribuir 5,1 sementes $\mathrm{m}^{-1}$ (cultivar Morgan MG652PW) e $407 \mathrm{Kg} \mathrm{ha}^{-1}$ de adubo (04-3016), com espaçamento entre linhas de $0,85 \mathrm{~m}$. A mesma foi tracionada por trator Valtra 1580 4x2 TDA, 106,6 kW (145 cv) de potência.

Para as medições da resistência mecânica do solo à penetração (RMSP) foi utilizado um Penetrógrafo eletrônico marca Eijkelkamp, modelo Penetrologger, bem como trado tipo rosca para a 
amostragem do teor de água no solo (TA). O teor de água foi determinado pelo método gravimétrico conforme descrito por Embrapa (2013). As amostras foram coletadas antes e logo após a colheita do milho para silagem.

A colheita do milho foi realizada linha a linha, utilizando uma colhedora de forragem da marca Pinheiro, modelo Max-10, acoplada a um trator da marca Massey Ferguson Modelo 275 com tração 4x2, com 55,16 kW $(75 \mathrm{cv})$ de potência. Para carregamento e transporte do material colhido utilizou-se carreta agrícola de arrasto de dois eixos (quatro rodados) com massa de $400 \mathrm{~kg}$ e capacidade de carga de aproximadamente $2000 \mathrm{~kg}$, tracionada por outro trator marca Massey Ferguson Modelo 275.

Avaliou-se RMSP nas camadas de 0,0-0,10, 0,10-0,20 e 0,20-0,30 m, e o TA nas camadas de 0,00,15 e 0,15-0,30 $\mathrm{m}$ antes e após a colheita do milho, seguindo uma malha amostral com 45 pontos espaçados em $20 \mathrm{~m}$. A malha amostral foi locada com estacas, utilizando-se de trena. Posteriormente, os pontos foram georreferenciados, utilizando-se equipamento GPS de navegação marca Garmin modelo Etrex 20.

Os dados foram submetidos à análise pela estatística descritiva utilizando o programa Minitab 17. Para a resistência mecânica do solo à penetração, aplicou-se a análise de variância, pelo teste F, a 5\% de probabilidade. Quando o teste F foi significativo, as médias foram comparadas pelo teste de Tukey, a 5\% de probabilidade, no programa Sisvar 4.3.

Para estimar a dependência espacial entre as amostras, bem como identificar se as variações foram sistemáticas ou aleatórias, foram utilizados modelos de semivariogramas, sendo a seleção realizada com base na menor soma de quadrados do resíduo (SQR) e melhor coeficiente de determinação $\left(\mathrm{R}^{2}\right)$, nos quais foram testados os modelos esférico, exponencial, gaussiano e linear. Os semivariogramas foram validados pelo método de isolinhas utilizando os programas Surfer e $\mathrm{Gs}^{+}$.

Nos semivariogramas ajustados foram definidos os seguintes parâmetros: efeito pepita (Co), patamar $(\mathrm{Co}+\mathrm{C})$ e alcance da dependência espacial (a). $\mathrm{O}$ quociente entre o efeito pepita e o patamar, $\mathrm{Co} /(\mathrm{Co}$ $+C)$, permitiu a classificação da dependência espacial dos resultados. Para a análise do grau de dependência espacial, foi utilizada a classificação de Cambardella et al. (1994), que considera como dependência espacial forte, os semivariogramas que têm efeito pepita igual a $25 \%$ do patamar, de dependência espacial moderada, quando o efeito pepita está entre 25 e 75\%, e dependência espacial fraca, quando o efeito pepita é maior que $75 \%$. Ainda avaliando os modelos ajustados, utilizou-se a técnica da validação cruzada para que fosse possível distinguir sua qualidade.

Após a estimação dos semivariogramas experimentais e o ajuste dos modelos teóricos, foi realizada a interpolação dos dados pelo método da krigagem, e posteriormente confecção dos mapas. Após o processamento dos dados e obtenção dos mapas de variabilidade, os mesmos foram comparados para obtenção dos resultados do grau de compactação das camadas avaliadas.

\section{RESULTADOS E DISCUSSÃO}

Na Tabela 1 são apresentados os parâmetros de medidas de tendência central (média e mediana), medidas de dispersão (amplitude, desvio padrão, coeficiente de variação), medidas de assimetria (coeficiente de assimetria e curtose) e teste de normalidade de Anderson-Darling para resistência mecânica do solo à penetração e o teor de água no solo. Observa-se que os valores de média e mediana encontraram-se próximos entre si, o que denota baixa dispersão dos dados, exceto para resistência mecânica 
do solo à penetração (RMSP) na profundidade de 0,20-

$0,30 \mathrm{~m}$, após a colheita, cujo valor da mediana é inferior ao da média. Segundo Marques Júnior et al. (2008) quando uma distribuição é simétrica, os valores da média e mediana são coincidentes, indicando que estão adequadas para o uso da geoestatística.

Tabela 1. Parâmetros de estatística descritiva para resistência mecânica do solo à penetração (MPa) e teor de água no solo $(\%)$.

\begin{tabular}{|c|c|c|c|c|c|c|c|}
\hline Média & Mediana & $\mathbf{A}$ & $\square$ & $\mathrm{CV}$ & Cs & $\mathrm{Ck}$ & $\mathrm{AD}$ \\
\hline \multicolumn{8}{|c|}{ RMSP 0,00-0,10 m (Antes da colheita) } \\
\hline 0,61 & 0,56 & 1,51 & 0,26 & 42,81 & 2,26 & 7,47 & $2,299^{\mathrm{A}}$ \\
\hline \multicolumn{8}{|c|}{ RMSP 0,10-0,20 m (Antes da colheita) } \\
\hline 1,12 & 1,07 & 2,18 & 0,46 & 41,47 & 0,77 & 0,99 & $0,489 \mathrm{~N}$ \\
\hline \multicolumn{8}{|c|}{ RMSP 0,20-0,30 m (Antes da colheita) } \\
\hline 1,79 & 1,72 & 2,07 & 0,41 & 23,26 & 0,68 & 0,52 & $0,748^{\mathrm{A}}$ \\
\hline \multicolumn{8}{|c|}{ TA $0,00-0,15 \mathrm{~m}$ (Antes da colheita) } \\
\hline 24,23 & 25,08 & 15,55 & 4,53 & 18,72 & $-0,51$ & $-0,89$ & $0,953^{\mathrm{A}}$ \\
\hline \multicolumn{8}{|c|}{ TA $0,15-0,30 \mathrm{~m}$ (Antes da colheita) } \\
\hline 22,37 & 23,55 & 11,99 & 3,62 & 16,20 & $-0,22$ & $-1,44$ & $1,565^{\mathrm{A}}$ \\
\hline \multicolumn{8}{|c|}{ RMSP 0,00-0,10 m (Depois da colheita) } \\
\hline 1,37 & 1,43 & 1,89 & 0,49 & 36,14 & 0,09 & $-1,03$ & $0,640^{\mathrm{N}}$ \\
\hline \multicolumn{8}{|c|}{ RMSP 0,10-0,20 m (Depois da colheita) } \\
\hline 1,87 & 1,81 & 3,22 & 0,63 & 34,15 & 1,70 & 4,61 & $1,457^{\mathrm{A}}$ \\
\hline \multicolumn{8}{|c|}{ RMSP 0,20-0,30 m (Depois da colheita) } \\
\hline 2,18 & 1,94 & 4,07 & 0,82 & 37,64 & 2,08 & 5,18 & $2,630^{\mathrm{A}}$ \\
\hline \multicolumn{8}{|c|}{ TA 0,00-0,15 m (Depois da colheita) } \\
\hline 24,59 & 24,89 & 10,51 & 2,19 & 8,91 & $-0,62$ & 0,93 & $0,559^{\mathrm{N}}$ \\
\hline \multicolumn{8}{|c|}{ TA $0,15-0,30 \mathrm{~m}$ (Depois da colheita) } \\
\hline 25,01 & 25,30 & 13,18 & 2,31 & 9,26 & 0,21 & 1,71 & $0,477 \mathrm{~N}$ \\
\hline
\end{tabular}

RMSP: resistência mecânica do solo a penetração, TA: teor de água no solo, A: amplitude, $\square$ desvio padrão, CV: coeficiente de variação (\%), Cs: coeficiente de assimetria, Ck: coeficiente de curtose, AD: valor do teste de normalidade de Anderson-Darling, A: distribuição Assimétrica, N: distribuição Normal.

Ao analisar os parâmetros de dispersão dos dados, verifica-se elevada amplitude e desvio padrão para o teor de água no solo (TA), tanto antes quanto após colheita, e para a RMSP após a colheita, nas profundidades de $0,00-0,10 \mathrm{~m}$ e $0,10-0,20 \mathrm{~m}$, com coeficientes de variação classificados como médios, altos ou muitos altos para a RMSP, e para o TA, médio antes da colheita, e baixo após a colheita (Fonseca \& Martins, 2010)

Cavichioli et al. (2012), avaliando a RMSP na linha e entrelinha de cana-de-açúcar em função da mecanização, encontraram coeficientes de variação altos para ambas as variáveis analisadas. Araújo et al.
(2014), em estudo da variabilidade espacial de atributos físicos em solo sob diferentes usos e manejo, encontraram o maior coeficiente de variação para o atributo RMSP (56,04\%), sendo classificado como muito alto.

Ainda na Tabela 1, para os coeficientes de assimetria, que quantifica o desvio de uma distribuição em relação a uma distribuição simétrica, observa-se pequena assimetria para RMSP de 0,00-0,10 m após colheita, assimetria moderada para o TA, tanto antes quanto após colheita, e RMSP 0,00-0,10 m e 0,20-0,30 $\mathrm{m}$ (antes da colheita). As demais variáveis apresentaram elevado coeficiente de assimetria. 
Em relação ao coeficiente de curtose, ou chamado grau de "achatamento" de uma distribuição de frequências, têm-se que a RMSP antes da colheita e após colheita nas profundidades de 0,10-0,20 m e 0,200,30 m, e o TA após a colheita apresentaram distribuição platicúrtica, apresentando curva de frequência mais aberta que a normal (ou mais achatada em sua parte superior), com os dados fracamente concentrados em torno de seu centro.

Para o TA antes da colheita e RMSP de 0,000,10 $\mathrm{m}$ após colheita, a distribuição foi leptocúrtica, ou seja, a mesma apresenta uma curva de frequência mais fechada que a normal (ou mais aguda ou afilada em sua parte superior), com os dados fortemente concentrados em torno de seu centro. Apesar dos dados de assimetria e curtose não seguirem uma distribuição normal, o TA após a colheita e a RMSP de 0,10-0,20 m antes e de 0,00-0,10 $\mathrm{m}$ após a colheita apresentaram distribuição normal, pelo teste de probabilidade de AndersonDarling. As demais variáveis analisadas apresentaram distribuição assimétrica

Pela análise de variância (Tabela 2), a RMSP demonstrou diferenças em todas as camadas avaliadas, com coeficientes de variação classificados como muito altos (> 30\%) conforme Fonseca e Martins (2010). Nota-se que os valores para a esse atributo vão aumentando à medida que se atinge as camadas subsuperficiais, com valores mais elevados após a colheita devido à pressão exercida sobre o solo decorrente do trafego de máquinas durante o processo.

Tabela 2. Análise de variância e teste de média para resistência mecânica do solo à penetração (MPa) antes e após a colheita.

\begin{tabular}{cccc}
\hline Fatores & RMSP 0,00-0,10 $\mathbf{~}$ & RMSP 0,10-0,20 $\mathbf{~}$ & RMSP 0,20-0,30 $\mathbf{~}$ \\
\hline Antes da colheita & $0,61 \mathrm{~b}$ & $1,12 \mathrm{~b}$ & $1,79 \mathrm{~b}$ \\
Depois da colheita & $1,37 \mathrm{a}$ & $1,87 \mathrm{a}$ & $2,17 \mathrm{a}$ \\
\hline Teste de F & $82,904^{*}$ & $39,919^{*}$ & $7,913^{*}$ \\
\hline $\mathrm{CV}(\%)$ & 39,98 & 37,34 & 32,76 \\
\hline
\end{tabular}

* Significativo a 5\% de probabilidade, pelo teste de F. CV (\%): coeficiente de variação.

Ribeiro (2009) compilou trabalhos sobre resistência mecânica a penetração em Latossolo Vermelho eutroférrico típico e estabeleceu uma classificação para esse atributo, sendo: baixa (0 a 2 $\mathrm{MPa}$ ), média (2 a $4 \mathrm{MPa})$, alta (4 a $6 \mathrm{MPa})$ e muito alta (acima de $6 \mathrm{MPa}$ ). Sendo assim, os valores de RMPS encontrados nesse ensaio são considerados baixos $(<2$ $\mathrm{MPa}$ ), exceto para a camada de 0,20-0,30 $\mathrm{m}$ após a colheita, que apresentou RMSP um pouco acima $(2,17$ $\mathrm{MPa}$ ), que é considerado um valor médio.

Segundo Tormena et al. (1998) e Molin et al. (2012), o sistema convencional de preparo do solo promove camadas menos compactadas em superfície e mais compactadas nas camadas subsuperficias $(0,20$ 0,40 m), devido ao efeito de acumulo das cargas dos implementos utilizados no preparo do solo, formando o conhecido "pé de grade". Aliado a isso, Vogel e Fey (2016) afirmam que o tráfego excessivo de máquinas associado às condições de alta umidade do solo pode agravar ainda mais os problemas de compactação do solo.

A Figura 1 apresenta a distribuição média da RMSP encontrada em profundidade no solo da área em estudo. Antes da colheita, os valores médios de RMSP variaram de 0,36 a 1,89 $\mathrm{MPa}$, na camada de 0 até $30 \mathrm{~cm}$ de profundidade, respectivamente, com média de 1,18 $\mathrm{MPa}$. O maior grau de compactação foi encontrado após a colheita, com variação foi de 0,58 a 2,27 MPa e média de 1,18 $\mathrm{MPa}$. 


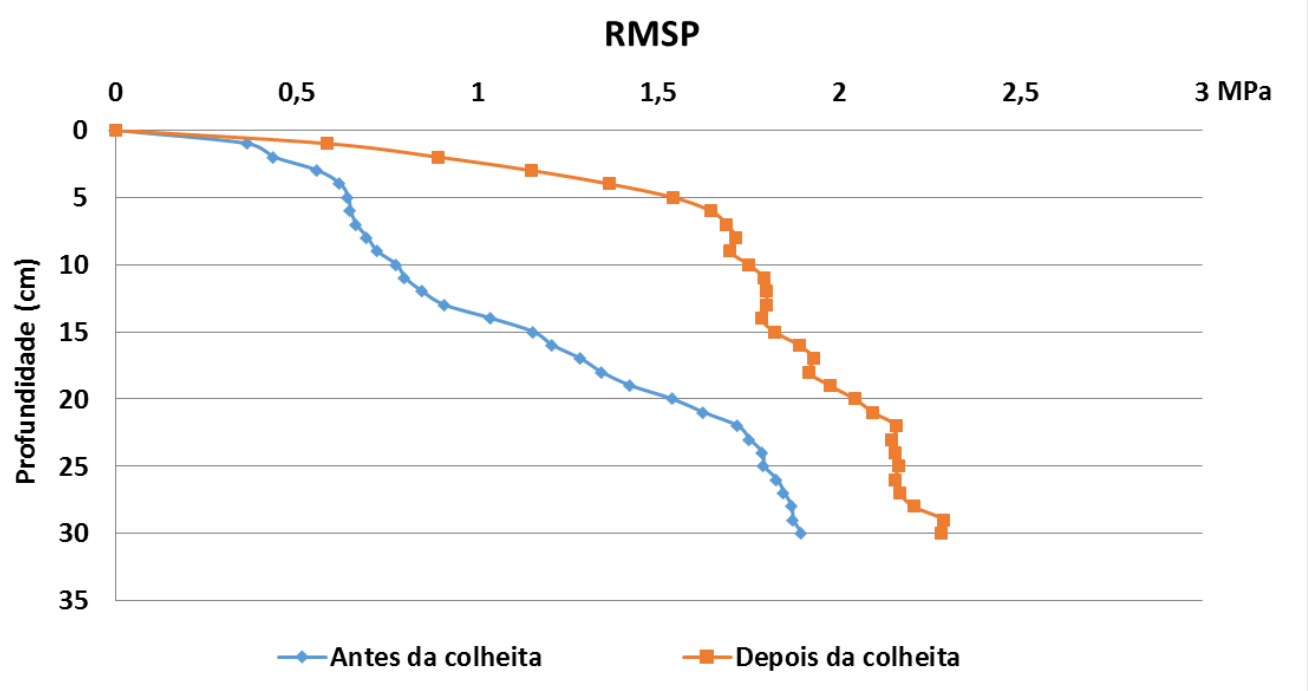

Figura 1. Perfil da resistência mecânica do solo à penetração (RMSP), em função da profundidade de avaliação.

Segundo Rodrigues (2014), os problemas de aumento da resistência mecânica do solo à penetração em camadas subsuperficiais podem ser atribuídos a três fatores: tipo de solo e classe textural, que o torna mais ou menos susceptível a compactação, tempo de uso, pois o maior tempo de uso do sistema resulta no acréscimo da RMSP, e o tráfego de máquinas, principalmente nas cabeceiras, que potencializa o processo de compactação.

O solo da área em estudo com alto teor de argila (61,1\%) associado ao tráfego excessivo de máquinas comprova a influência dos fatores supracitados sobre a resistência mecânica do solo a penetração. De acordo com Lima et al., (2013), a movimentação de máquinas promove uma menor porosidade e maior densidade do solo, resultando em elevada compactação e consequentemente maior resistência mecânica do solo à penetração, o que corrobora com os resultados encontrados.

Em relação às análises geoestatísticas (Tabela 3), verifica-se que modelo de semivariograma que se ajustou foi o esférico para as variáveis RMSP nas camadas de 0,10-0,20 0,20-0,30 m antes e após colheita, e TA 0,00-0,15 e 0,15-0,30 m antes da colheita. As demais variáveis obtiveram efeito pepita puro.

Tabela 3. Parâmetros ajustados ao semivariograma da resistência mecânica do solo à penetração e do teor de água no solo.

\begin{tabular}{|c|c|c|c|c|c|c|c|c|}
\hline Modelo & $\mathrm{Co}^{(1)}$ & $\mathrm{Co}+\mathrm{C}^{(2)}$ & $\mathbf{C}^{(3)}$ & $\mathbf{a}^{(4)}$ & $\mathbf{R}^{2(5)}$ & $\mathrm{SQR}^{(6)}$ & $\operatorname{ADE}^{(7)}$ & Classe \\
\hline \multicolumn{9}{|c|}{ RMSP 0,00-0,10 m (Antes da colheita) } \\
\hline EPP(8) & - & - & - & - & - & - & - & - \\
\hline \multicolumn{9}{|c|}{ RMSP 0,10-0,20 m (Antes da colheita) } \\
\hline $\mathrm{ESF}^{(9)}$ & 0,009 & 0,228 & 0,219 & 35,30 & 0,283 & $2,10 \times 10^{-3}$ & 0,961 & Forte \\
\hline \multicolumn{9}{|c|}{ RMSP 0,20-0,30 m (Antes da colheita) } \\
\hline ESF & 0,003 & 0,168 & 0,165 & 37,10 & 0,197 & $2,75 \times 10^{-3}$ & 0,982 & Forte \\
\hline \multicolumn{9}{|c|}{ TA $0,00-0,15 \mathrm{~m}$ (Antes da colheita) } \\
\hline ESF & 0,010 & 24,56 & 24,550 & 81,30 & 0,975 & 4,26 & 1,000 & Forte \\
\hline \multicolumn{9}{|c|}{ TA $0,15-0,30 \mathrm{~m}$ (Antes da colheita) } \\
\hline ESF & 0,010 & 15,77 & 15,760 & 75,40 & 0,982 & 1,29 & 0,999 & Forte \\
\hline \multicolumn{9}{|c|}{ RMSP 0,00-0,10 m (Depois da colheita) } \\
\hline EPP & - & - & - & - & - & - & - & - \\
\hline
\end{tabular}




\begin{tabular}{|c|c|c|c|c|c|c|c|c|}
\hline \multicolumn{9}{|c|}{ RMSP 0,10-0,20 m (Depois da colheita) } \\
\hline ESF & 0,006 & 0,377 & 0,371 & 31,40 & 0,460 & $7,70 \times 10^{-4}$ & 0,984 & Forte \\
\hline \multicolumn{9}{|c|}{ RMSP 0,20-0,30 m (Depois da colheita) } \\
\hline ESF & 0,012 & 0,624 & 0,612 & 32,20 & 0,475 & $2,59 \times 10^{-3}$ & 0,981 & Forte \\
\hline \multicolumn{9}{|c|}{ TA $0,00-0,15 \mathrm{~m}$ (Depois da colheita) } \\
\hline EPP & - & - & - & - & - & - & - & - \\
\hline \multicolumn{9}{|c|}{ TA $0,15-0,30 \mathrm{~m}$ (Depois da colheita) } \\
\hline EPP & - & - & - & - & - & - & - & - \\
\hline
\end{tabular}

(1): Efeito pepita, (2): Patamar, (3): Variância, (4): Alcance, (5): coeficiente de determinação, (6): soma dos quadrados do erro, (7): avaliador da dependência espacial, (8): Efeito Pepita Puro. (9): Modelo Esférico.

Segundo Grego e Vieira (2005), o modelo matemático esférico é o que predomina nos trabalhos em ciência do solo, fato esse que se confirma no presente estudo. Estes resultados foram também confirmados por Corá e Beraldo (2006) que estudaram modelos de ajuste dos semivariogramas para os atributos do solo e relataram que os modelos esférico e exponencial são os mais encontrados. Segundo Santos (2006), os modelos de ajustes são importantes no cálculo dos valores não amostrados e também na interpretação dos valores amostrais vizinhos, conferindo assim melhor estimativa de alguns pontos, e, por fim, descrevem o fato da dependência espacial.

Para as variáveis que obtiveram ajustes de semivariogramas, a avaliação da dependência espacial (ADE) apresentou classificação forte, o que denota que essas variáveis encontram-se de forma heterogênea, sendo assim a malha amostral foi suficiente para se detectar a dependência espacial nas mesmas.

Definidos os semivariogramas, fez-se a interpolação dos valores na área de estudo por meio da krigagem, e, a partir dessas estimativas, foram construídos os mapas de isolinhas para cada uma das variáveis (Figuras 2 e 3). Ao comparar os mapas de RMSP (Figuras 2a, 2b, 2c e 2d), nota-se que houve um incremento de RMSP após a colheita, em ambas as camadas avaliadas, ocasionado pelo intenso tráfego de máquinas durante o processo de colheita. Apesar do incremento, os valores em ambas as camadas avaliadas, em média, se encontram abaixo do limite crítico de desenvolvimento vegetativo (Ribeiro, 2009).

Nora et al. (2013), estudando a variabilidade dos atributos químico-físicos do solo e sua relação com a produtividade do milho, também em solo muito argiloso, encontraram valores parecidos de RMSP, com a média mais alta $(2,2 \mathrm{MPa})$ na camada subsuperficial.

Valores de resistência mecânica do solo à penetração de 2,0 a 4,0 MPa, segundo Tavares Filho e Tessier (2009), podem restringir ou mesmo impedir o crescimento e o desenvolvimento das raízes, porém a compactação do solo é mais prejudicial em solo seco, sendo que em condições de maior conteúdo de água pode haver crescimento radicular em valores de resistência mecânica do solo à penetração superiores a 4,0 MPa. De acordo com Cunha et al. (2007), altos valores de resistência mecânica do solo à penetração são admitidos em plantio direto.

Segundo Pacheco e Cantalice (2011), a compressão do solo depende de fatores internos e externos. Dentre os fatores internos está a composição mineralógica, textura, estrutura, umidade do solo e matéria orgânica, os fatores externos podem ser atribuídos principalmente à energia de compactação aplicada ao solo, que pode ser natural, pela ação do impacto das gotas de chuva, ou artificial por meio do pisoteio de animais ou de humanos e pelo uso de equipamentos agrícolas. 


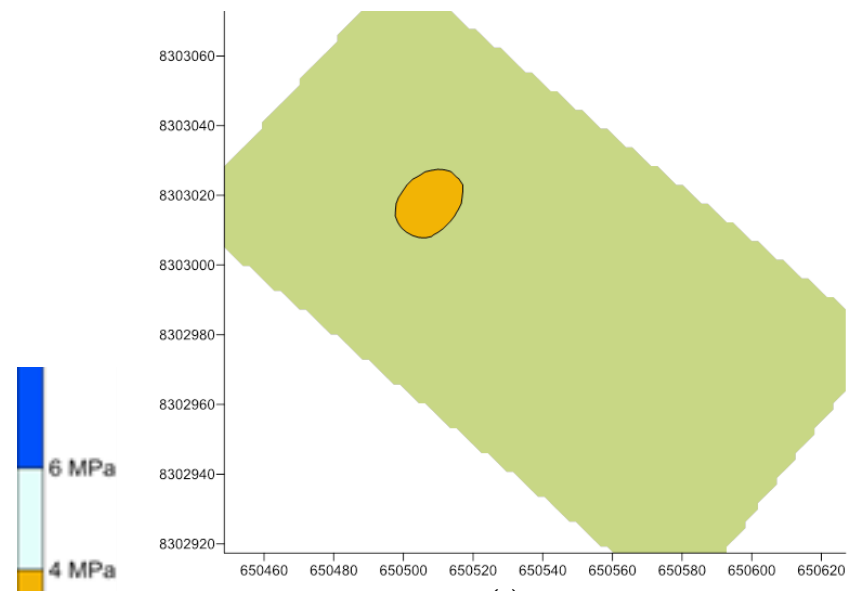

(a)

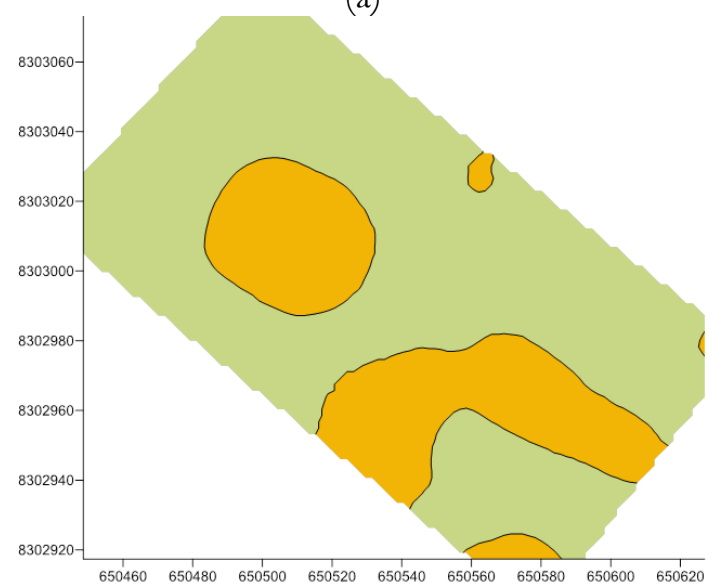

(c)

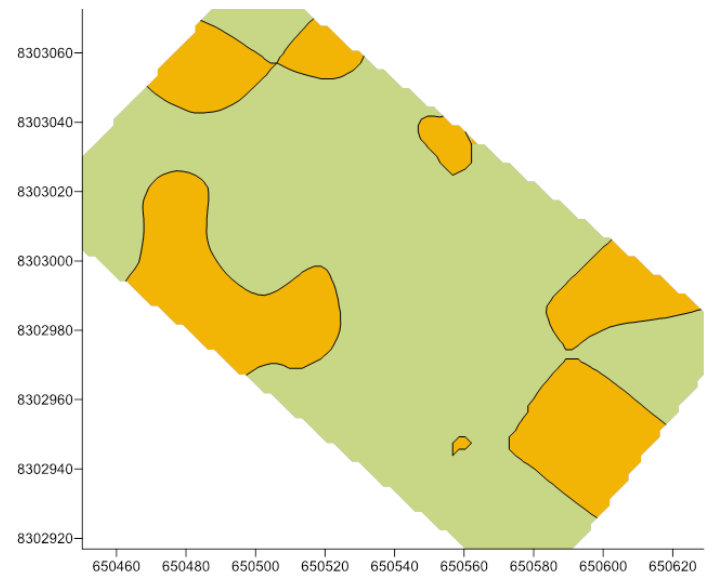

(b)

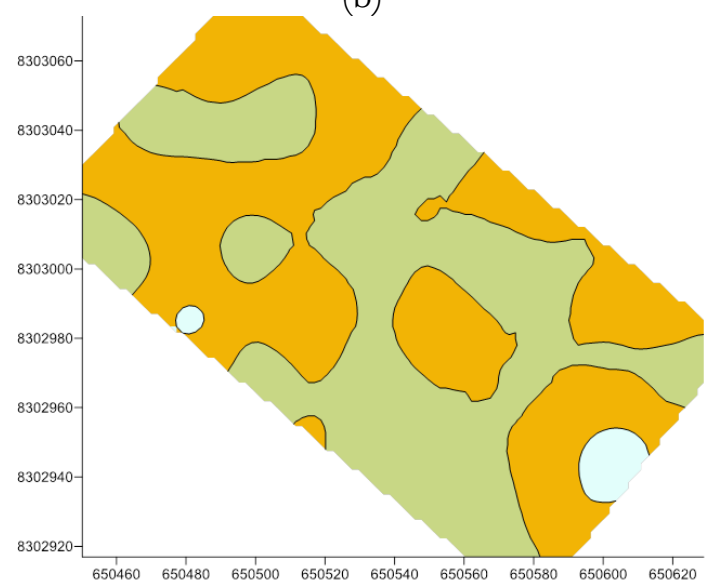

(d)

Figura 2. Mapas de krigagem para resistência mecânica do solo à penetração (MPa): 0,10-0,20 m (antes da colheita) (a), 0,10-0,20 m (depois da colheita) (b), 0,20-0,30 m (antes da colheita) (c), 0,20-0,30 m (depois da colheita) (d).

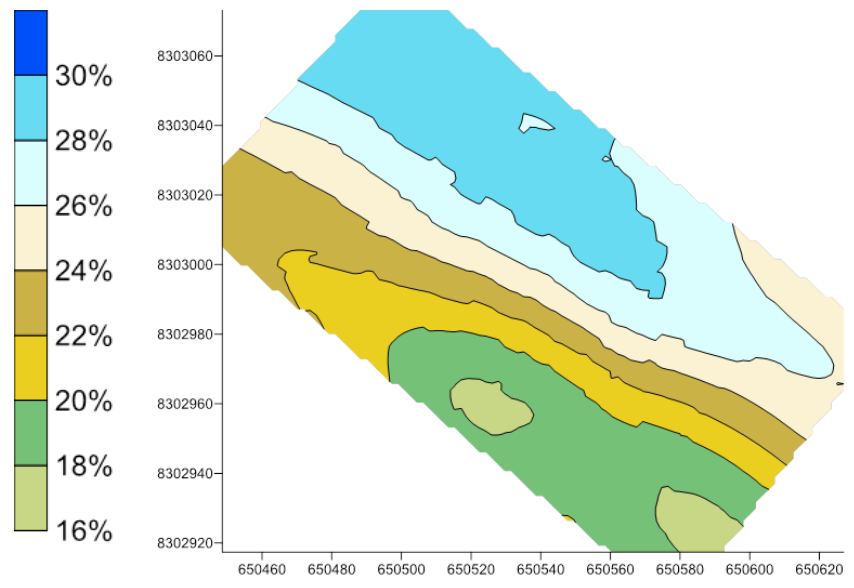

(a)

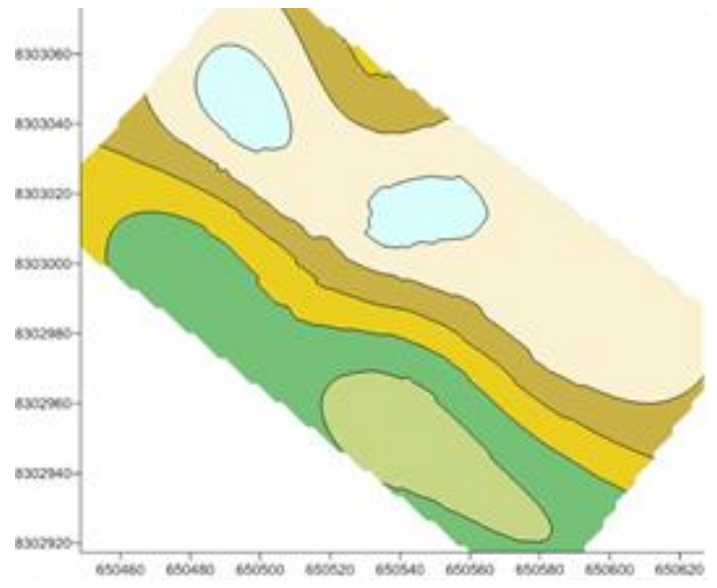

(b)

Figura 3. Mapas de krigagem para teor de água no solo (\%): 0,00-0,15 m (antes da colheita) (a), 0,15-0,30 m (antes da colheita) (b).

Para Tormena e Roloff (1996), os aspectos inerentes à variabilidade temporal, espacial da resistência mecânica do solo à penetração estão relacionados com os processos de adensamento do solo após o preparo, compactação pelo tráfego de máquinas, e principalmente pelas variações do conteúdo de água 
do solo com o tempo, o qual acompanha a dinâmica do clima em áreas não irrigadas. Os solos que possuem um determinado nível de desenvolvimento estrutural apresentam um grau elevado de variabilidade espacial e temporal das suas propriedades físicas, inclusive aquelas importantes para o desenvolvimento radicular.

Analisando os mapas do TA antes da colheita (Figuras 3a e 3b), verifica-se que ocorreu uma grande variabilidade dos valores ao longo de toda a área, com valores variando entre 16 e $28 \%$ de umidade, e comportamento da umidade em faixas, fato que pode ser explicado devido à cultura ter sido semeada em nível (contra o declive), contribuindo para a retenção de água no solo em ambas as camadas avaliadas.

Após a colheita, não houve dependência espacial para o teor de água no solo, o que não permitiu a confecção dos mapas de krigagem. Ressalta-se que na camada de 0,00-0,15 m, a umidade média foi de $24,4 \%$, variando de 18,8 a $29,3 \%$, e na profundidade de 0,15 0,30 m, a média foi de 25,0\%, com mínimo de 19,1\% e máximo de 32,3\%. Como não foi feito nenhum controle de plantas daninhas na área, mesmo após a retirada da cultura, a massa verde presente no solo continuou contribuindo para a retenção de água.

O aumento do teor de água do solo gera uma lubrificação das partículas do solo, o que faz com que ocorra uma redução na RMSP (Cunha, 2009). Seixas (2000) observou que o aumento do teor de água do solo resulta em redução da densidade do solo, causando destruição na estrutura do solo. O mesmo ainda afirma que os efeitos do conteúdo de água alteram-se de acordo com as características do solo e o esforço de compactação aplicado sobre este. Se o teor de água aumenta, a resistência à compactação diminui, devido à maior lubrificação das partículas.

Conforme a Tabela 4 verifica-se que nas camadas de 0,10-0,20, 0,20-0,30 m (antes da colheita) e 0,10-0,20 (após a colheita), 100\% da área apresentou RMSP abaixo de 4,0 MPa, que pode ser caracterizado como nível médio de compactação (Ribeiro, 2009). A camada de 0,20-0,30 m (depois da colheita) mostrou um pequeno percentual de área acima de 4,0 $\mathrm{MPa}$, representando $2,2 \%$.

Tabela 4. Área acima e abaixo de 4 MPa para resistência mecânica do solo à penetração, nas profundidades avaliadas.

\begin{tabular}{cccc}
\hline Variável & $\begin{array}{c}\text { Área acima } \\
\mathbf{4} \mathbf{~} \mathbf{P a}\left(\mathbf{m}^{\mathbf{2}}\right)\end{array}$ & $\begin{array}{c}\text { Área abaixo } \\
\mathbf{4} \mathbf{~} \mathbf{P a}\left(\mathbf{m}^{\mathbf{2}}\right)\end{array}$ & $\begin{array}{c}\text { Área Total } \\
\left.\mathbf{( m}^{\mathbf{2}}\right)\end{array}$ \\
\hline RMSP 0,10-0,20 m (Antes da colheita) & 0 & 16214,1 & 16214,1 \\
RMSP 0,20-0,30 m (Antes da colheita) & 0 & 16214,1 & 16214,1 \\
RMSP 0,10-0,20 m (Depois da colheita) & 0 & 16224,64 & 16224,6 \\
RMSP 0,20-0,30 m (Depois da colheita) & 354,54 & 15870,09 & 16224,6 \\
\hline
\end{tabular}

Considerando o limite de 4,0 $\mathrm{MPa}$ para realização de técnicas de preparo para a descompactação, como a subsolagem, nas condições em que se encontra a área em estudo, essa operação poderia ser realizada de forma pontual, ou seja, somente nos pontos que apresentam compactação. $\mathrm{Na}$ agricultura convencional, normalmente faz-se a opção por mobilizar a área toda ou não fazer a operação. $\mathrm{Na}$ opção de fazer a operação, o uso da agricultura de precisão pode permitir uma economia de tempo, mão de obra e combustíveis (Vogel e Fey, 2016).

Para a validação cruzada (Tabela 5) os melhores resultados foram observados para RMSP nas camadas 0,20-0,30 m e para os TA nas camadas 0,00-0,15 e 0,150,30 m (antes da colheita), que apresentaram valores de coeficientes de regressão (CR) mais próximos ao ideal (1), sendo 0,69, 0,95 e 0,93, respectivamente, e coeficientes de determinação $\left(R^{2}\right)$ mais elevados, acima 
de $59 \%$, exceto para a RMSP na camada de $0,20-0,30$

$\mathrm{m}$, que apresentou coeficiente de determinação baixo

$(19,2 \%)$.

Tabela 5. Parâmetros da validação cruzada da resistência mecânica do solo à penetração e teor de água no solo.

\begin{tabular}{ccccc|cc}
\hline & \multicolumn{3}{c|}{ Antes da colheita } & \multicolumn{2}{c}{ Depois da colheita } \\
& RMSP & \multicolumn{2}{c}{ Teor de água no solo } & \multicolumn{2}{c}{ RMSP } \\
& $\mathbf{0 , 1 0 - 0 , 2 0 ~} \mathbf{~ m}$ & $\mathbf{0 , 2 0 - 0 , 3 0 ~} \mathbf{~ m}$ & $\mathbf{0 , 0 0 - 0 , 1 5} \mathbf{~ m}$ & $\mathbf{0 , 1 5 - 0 , 3 0 ~} \mathbf{~ m}$ & $\mathbf{0 , 1 0 - 0 , 2 0 ~} \mathbf{~ m}$ & $\mathbf{0 , 2 0 - 0 , 3 0 ~} \mathbf{~ m}$ \\
\hline $\mathrm{CR}$ & 0,322 & 0,691 & 0,952 & 0,931 & $-0,573$ & $-0,399$ \\
$\mathrm{Y}$ & 0,76 & 0,54 & 1,19 & 1,54 & 2,94 & 3,04 \\
$\mathrm{SE}$ & 0,272 & 0,216 & 0,119 & 0,118 & 0,427 & 0,357 \\
$\mathrm{R}^{2}$ & 0,032 & 0,192 & 0,596 & 0,592 & 0,040 & 0,028 \\
\hline
\end{tabular}

CR: Coeficiente de regressão, Y: Intercepto, SE: Erro padrão, R²: Coeficiente de determinação. RMSP: resistência mecânica do solo à penetração.

O alto valor de CR indica baixo desvio da nuvem de pontos em torno da reta ideal, que possui coeficiente angular de valor 1 e corta a origem do eixo y (intercepto) no valor zero. O erro padrão (SE) próximo de zero, associados aos demais parâmetros, demonstra que o modelo representa com boa precisão os dados. Porém, esse fato não ocorreu nos resultados encontrados, apresentando uma relação inversa entre os parâmetros avaliados. A alta dispersão dos dados também pode ser comprovada quando se observa os parâmetros de estatística descritiva que apresentou altos valores de coeficiente de variação.

\section{CONCLUSÕES}

A utilização dos mapas de krigagem possibilitou a identificação de uma elevada variabilidade da resistência mecânica do solo à penetração e do teor de água no solo. Os maiores valores de resistência mecânica do solo a penetração foram obtidos após a colheita nas camadas de 0,10-0,20 e 0,20-0,30 m de profundidade.

O tráfego de máquinas durante a colheita do milho causou incremento da resistência mecânica do solo à penetração, porém atingindo níveis abaixo do descrito como limite crítico de penetração das raízes, não havendo necessidade de preparo convencional para implantação da próxima cultura.

\section{AGRADECIMENTOS}

Ao Instituto Federal Goiano Campus Ceres, pelo apoio na realização do experimento e concessão de bolsa de iniciação científica.

\section{REFERÊNCIAS BIBLIOGRÁFICAS}

Araújo DR, Sombra WA, Andrade RR, Amorim MQ. Variabilidade espacial de atributos físicos em solo submetidos a diferentes usos e manejos. Revista Caatinga. 2014;27:101-115.

Batista PHD, Montenegro AAA, Almeida GLP, Tavares UE, Rodrigues RAS. Variabilidade espacial da resistência mecânica à penetração e teor de água em Neossolo cultivado com banana no Agreste Pernambucano. Revista Engenharia na Agricultura. 2019;27:54-60.

Beutler AN, Centurion JF. Efeito do conteúdo de água e da compactação do solo na produção de soja. Pesquisa Agropecuária Brasileira. 2003;38:849856.

Cambardella CA, Moorman TB, Novak JM, Parkin TB, Karlen DL, Turco RF, Konopka AE. Field-scale variability of soil properties in central Iowa soils. Soil Science Society of American Journal. 1994;58:1501-1511. 
Cavichioli FA, Furlani CEA, Toledo A, Silva RP. Resistência mecânica do solo a penetração na fileira e entrefileira de cana-de-açúcar em função da mecanização. Engenharia na agricultura. 2012;20:46-51.

Coelho DS, Cortez JW, Olszevski N. Variabilidade espacial da resistência mecânica à penetração em Vertissolo cultivado com manga no perímetro irrigado de Mandacuru, Juazeiro, Bahia, Brasil. Revista Brasileira de Ciência do Solo. 2012;36:755-763.

Corá JE, Beraldo JMG. Variabilidade espacial de atributos do solo antes e após calagem e fosfatagem em doses variadas na cultura de canade-açúcar. Engenharia Agrícola. 2006;26:374387.

Cunha EQ, Balbino LC, Stone LF, Leandro WM, Oliveira GC. Influência de rotações de culturas nas propriedades físico-hídricas de um Latossolo Vermelho em plantio direto. Engenharia Agrícola. 2007;27:665-667.

Cunha JPAR, Junior PCC, Souza JN, Borges EN, Reis EF. Compactação do solo sob sistemas de manejo convencionais e conservacionistas. Engenharia na agricultura. 2009;17:155-162.

Drescher MS, Eltz FLF, Denardim JE, Faganello A, Drescher GL. Resistência à penetração e rendimento da soja após a intervenção mecânica em Latossolo Vermelho sob plantio direto. Revista Brasileira de Ciência do Solo. 2012;36:1836-1844.

EMBRAPA - EMPRESA BRASILEIRA DE PESQUISA AGROPECUÁRIA. Sistema Brasileiro de classificação de Solos. 3ed. Brasília: Embrapa; 2013.

Fonseca JS, Martins GA. Curso de estatística. 6ed. São Paulo: Atlas; 2010.

Grego CR, Vieira SR. Variabilidade espacial de propriedades físicas do solo em uma parcela experimental. Revista Brasileira de Ciência do Solo. 2005;29:169-177.

Lima IMA, Araújo MC, Barbosa RS. Avaliação das propriedades físicas do solo em sistemas silvipastoris, região centro-norte, estado do Piauí. Agropecuária Científica do Semiárido. 2013;9:117-124
Marques júnior J, Souza ZM, Pereira GT, Barbieri DM. Variabilidade espacial de matéria orgânica, P, K e CTC de um Latossolo cultivado com cana-deaçúcar por longo período. Revista de Biologia e Ciências da Terra. 2008;8:143-152.

Molin JP, Dias CTS, Carbonera L. Estudos com penetrometria: Novos equipamentos e amostragem correta. Revista Brasileira de Engenharia Agrícola e Ambiental. 2012;16:584590 .

Nora DD, Amado TJC, Alba B, Bortolotto RP, Keller C. Agricultura de precisão: variabilidade dos atributos químico-físicos do solo e Relação com a produtividade do milho. Engenharia na agricultura. 2013;21:59-68.

Oliveira filho FX, Miranda NO, Medeiros JF, Silva PCM, Mesquita FO, Costa TKG. Zonas de manejo para preparo de solo na cultura da canade-açúcar. Revista Brasileira de Engenharia Agrícola e Ambiental. 2015;19:186-193.

Pacheco EP, Cantalice JRB. Análise de trilha no estudo dos efeitos de atributos físicos e matéria orgânica sobre a compressibilidade e resistência a penetração de um Argissolo cultivado com canade-açúcar. Revista Brasileira de Ciência do Solo. 2011;35:417-428.

Ribeiro CA. Variabilidade espacial da resistência mecânica do solo à penetração em áreas mecanizadas em função do número de cortes da cana-de-açúcar (Saccharum officinarum) [Dissertação]. Jaboticabal: Universidade Estadual Paulista; 2009.

Rodrigues FS. Variabilidade espacial da resistência mecânica do solo à penetração em área sob sistema plantio direto [Dissertação]. Dourados: Universidade Federal de Grande Dourados; 2014.

Santos NT. Estatística espacial aplicada. Viçosa: UFV; 2006.

Seixas F. Compactação do solo devido à colheita de madeira. Piracicaba: Esalq; 2000.

Souza ZM, Marques júnior J, Pereira GT. Geoestatística e atributos do solo em áreas cultivadas com canade-açúcar. Ciência Rural. 2010;40:48-56. 
Stefanoski DC, Santos GG, Marchão RL, Petter FA, Pacheco LP. Uso e manejo do solo e seus impactos sobre a qualidade física. Revista Brasileira de Engenharia Agrícola e Ambiental. 2013;17:1301-1309.

Tavares filho J, Tessier D. Compressibility of oxisol aggregate e sunder no-till in response to soil water potential. Revista Brasileira de Ciência do Solo. 2009;33:1525-1533.

Tormena CA, Roloff G, Sá JCM. Propriedades físicas do solo sob plantio direto influenciado por calagem, preparo inicial e tráfego. Revista Brasileira de Ciência do Solo. 1998;22:301-309.

Tormena CA, Roloff G. Dinâmica da resistência à penetração de um solo sob plantio direto. Revista Brasileira de Ciência do Solo. 1996;20:333-339.

Vogel GF, Fey R. Resistência mecânica à penetração em diferentes sistemas de uso do solo. Revista de Agricultura Neotropical. 2016;3:21-26 